\title{
REVIEW
}

\section{Clinical review: Use of renal replacement therapies in special groups of ICU patients}

\author{
Eric AJ Hoste ${ }^{1,2 *}$ and Annemieke Dhondt ${ }^{3}$
}

\begin{abstract}
Acute kidney injury (AKI) in ICU patients is typically associated with other severe conditions that require special attention when renal replacement therapy (RRT) is performed. RRT includes a wide range of techniques, each with specific characteristics and implications for use in ICU patients. In the present review we discuss a wide range of conditions that can occur in ICU patients who have AKI, and the implications this has for RRT. Patients at increased risk for bleeding should be treated without anticoagulation or with regional citrate anticoagulation. In patients who are haemodynamically unstable, continuous therapies are most often employed. These therapies allow slow removal of volume and guarantee a stable blood $\mathrm{pH}$. In patients with cerebral oedema, continuous therapy is recommended in order to prevent decreased cerebral blood flow, which will lead to cerebral ischemia. Continuous therapy will also prevent sudden change in serum osmolality with aggravation of cerebral oedema. Patients with hyponatraemia, as in liver failure or decompensated heart failure, require extra attention because a rapid increase of serum sodium concentration can lead to irreversible brain damage through osmotic myelinolysis. Finally, in patients with severe lactic acidosis, RRT can be used as a bridging therapy, awaiting correction of the underlying cause. Especially in ICU patients who have severe AKI, treatment with RRT requires balancing the pros and cons of different options and modalities. Exact and specific guidelines for RRT in these patients are not available for most clinical situations. In the present article we provide an update on the existing evidence.
\end{abstract}

*Correspondence: Eric.Hoste@UGent.be

'Department of Intensive Care Medicine, ICU, 2-K12C, Ghent University Hospital, De Pintelaan 185, 9000 Gent, Belgium

Full list of author information is available at the end of the article

\section{Introduction}

The use of renal replacement therapy (RRT) in ICU patients is increasing over the years [1-3]. This increase may be explained by a higher number of ICU patients with older age and increased comorbidity, as well as by a decrease of exclusion criteria for RRT, such as in special groups of ICU patients - for example, those with haemodynamic instability and bleeding.

RRT encompasses a broad range of techniques (Table 1). A distinction can be made based on duration (intermittent, continuous), membrane permeability (high flux, low flux), diffusion (haemodialysis) or convection (haemofiltration) or a combination of these (haemodiafiltration), and equipment used (machine for regular haemodialysis, single-pass batch system or machines that are specifically developed for continuous renal replacement therapy (CRRT)).

Examples of continuous techniques include continuous haemodialysis, continuous venovenous haemofiltration $(\mathrm{CVVH})$ and continuous venovenous haemodialfiltration (CVVHDF). Intermittent therapies include haemodialysis (HD) with varying duration, ranging from short (2 to 4 hours) to long (6 to 12 hours) as in sustained lowefficiency daily dialysis (or hybrid therapy, as it alternatively named). This form of intermittent RRT can be performed with a classic dialysis machine, and its dialysis characteristics are intermediate between classic HD and CRRT. Blood flow and dialysate flows are decreased and the treatment time is increased up to 6 to 12 hours per day. This treatment allows better haemodynamic tolerance and some hours per day off-machine, while the dialysis dose is maintained [4]. Intermittent haemodiafiltration can be applied as well, at least if online ultrapure water is available in the ICU.

Peritoneal dialysis (PD) is very seldom used for the treatment of acute kidney injury (AKI) in ICU patients. Data on the use of this modality are scarce (only 240 adult patients were studied in three randomised studies) and come from developing countries. An initial report on PD demonstrated increased mortality of patients randomised to this RRT modality in the setting of AKI [5]. However, two other studies (one of which was published twice) found that the outcome of high-volume 


\begin{tabular}{ll}
\hline Basis & Modalities \\
\hline Duration of therapy & Intermittent versus continuous \\
Membrane permeability & High flux versus low flux \\
Treatment technique & Diffusion or haemodialysis versus convection or haemofiltration versus a combination or haemodiafiltration \\
Equipment & Single-pass batch system versus regular haemodialysis machine versus continuous renal replacement therapy machine \\
Anticoagulation used & No anticoagulation versus heparin (low molecular weight or unfractionated) versus citrate versus less frequently used \\
& strategies (for example, prostacyclin or argatroban) \\
\hline
\end{tabular}

and continuous PD was comparable with daily HD or CVVHDF in AKI [6-8]. An important limitation of these last studies is that they excluded patients who died on day 1 after randomisation, thereby rendering a more favourable outcome.

Each of these RRT modalities has specific characteristics with implications for their use in specific ICU patient groups.

\section{Patients with increased risk for haemorrhage}

Most modalities of RRT, with the exception of PD, need anticoagulation to prevent clotting in the extracorporeal circuit, thereby increasing the circuit life and dose of RRT and containing the cost for replacement of a new filter and tubin. The downside of the use of anticoagulants is the increased risk for haemorrhage. The most frequently used anticoagulant in ICU patients is unfractionated heparin, followed by low molecular weight heparin and regional citrate anticoagulation [9].

\section{No anticoagulation}

In most patients, a 2-hour dialysis session can be performed without anticoagulation; but in patients with thrombocytopaenia and coagulation disorders, even longer sessions up to CRRT can be performed without clotting. The use of heparin-coated membranes facilitates this session extension. Intermittent flushing with saline can also postpone clotting. If haemofiltration is applied, predilution is preferred to prevent haemoconcentration in the circuit. In addition, in postdilution mode, the filtration fraction - calculated as effluent rate/plasma flow rate - should be below 20 to $25 \%$.

If no anticoagulation is allowed, catheter locks used to fill up dialysis catheters between dialysis session should be heparin-free as leakage of heparin through the side holes is demonstrated. For that purpose, citratecontaining solutions can be used as a catheter lock.

In the absence of contraindications, such as diverticulitis or recent abdominal surgery, PD in theory can be an alternative RRT modality in patients at high risk for bleeding.

\section{Regional anticoagulation with citrate or with} heparin/protamine

Regional anticoagulation with citrate is based on its binding with calcium. Citrate, infused into the afferent bloodline, binds ionised calcium and hence blocks coagulation [10-12]. The removal of citrate is dependent on the dialysate flow and/or ultrafiltration rate. Citrate may enter the systemic circulation and can induce hypocalcaemia, resulting in cardiac problems. Calcium substitution with a systemic calcium infusion is therefore nearly always necessary, especially in CRRT. The removal of citrate per minute is greater in dialysis compared with CVVH. Citrate anticoagulation is therefore theoretically safer in intermittent haemodialysis compared with CVVH, whereby less citrate is removed. Many different citrate schemes are used for predilution and postdilution CVVH, continuous venovenous haemodialysis (CVVHD) and CVVHDF, and we would like the reader to refer to specific texts on this topic $[11,12]$. Haemodialysis with citrate can be performed with calcium-containing dialysate or with calcium-free dialysate, preferred for short and long sessions, respectively. In continuous modalities, and when using calcium-free dialysate, ionised calcium must be measured rigorously and calcium needs to be re-infused to prevent hypocalcaemia. Citrate accumulation can be monitored by the total to ionised calcium ratio. When this is above 2.5 , the citrate dose should be decreased and calcium reinfused. In patients with reduced citrate metabolism, such as in liver failure and in patients with pre-existing hypocalcaemia and/or hypomagnesaemia, extra caution is warranted.

Regional citrate anticoagulation is increasingly used, and is currently recommended by the Kidney Disease: Improving Global Outcomes consensus group as the preferred anticoagulant for CRRT both in patients with and without increased bleeding risk (level of evidence $2 \mathrm{~B}$ and $2 \mathrm{C}$, indicating a suggestion based on low quality of evidence) (data not yet published; M Schetz, personal communication). Several studies have demonstrated the feasibility of this technique with different protocols. Regional citrate anticoagulation resulted in an increased filter life in some studies, less bleeding complications, and in one study was even associated with increased survival when compared with low molecular weight heparin, although this could not be confirmed in another study where unfractionated heparin was the comparator [13-17].

Although regional anticoagulation was originally described with unfractionated heparin and protamine 
$[18,19]$, its use has decreased in parallel with the increasing popularity of citrate. Protamine has several side effects such as anaphylaxis, hypotension, cardiac depression, leukopaenia and thrombocytopaenia. Further, there is risk for a rebound anticoagulant effect, due to the shorter half-life of protamine compared with heparin. Regional anticoagulation with heparin-protamine is therefore no longer recommended [20].

\section{Other anticoagulation strategies}

Prostaglandins and the synthetic protease inhibitor nafamostat mesilate inhibit platelet aggregation and adhesion. In CRRT, prostaglandin $\mathrm{I}_{2}$ and prostaglandin $\mathrm{E}_{1}$ administered in a fixed dose resulted in less filter clotting and less bleeding complications in a small prospective randomised study ( $n=50$ patients) [21]. Prostaglandin $I_{2}$ has also been successfully used in patients with combined AKI and acute liver failure, who were at increased risk for bleeding [22]. Prostaglandin induces vasodilation and therefore hypotension, however, and may also lead to increased intracranial hypertension and decreased cerebral perfusion pressure [23]. These side effects and the cost of this anticoagulation strategy hindered its widespread introduction and use.

\section{Patients with heparin-induced thrombocytopaenia type II} When heparin-induced thrombocytopaenia type II is suspected or confirmed, the administration of unfractionated heparin and low molecular weight heparin is contraindicated. In that respect, catheter locks, rinsing solutions, dialyser membranes, catheters, and so forth, must also be heparin free. Besides regional citrate anticoagulation (or prostacyclin), the following anticoagulants could be used in patients with heparin-induced thrombocytopaenia type II.

Argatroban, a direct thrombin inhibitor, is mainly hepatically metabolised with a short half-life of 35 minutes in patients with end-stage kidney disease (ESKD). The activated clotting time and the activated partial thromboplastin time can be used for monitoring. Only minor extracorporeal clearance with high-flux membranes is demonstrated. Argatroban, due to its short half-life, is a safe anticoagulant in patients with renal failure without hepatic impairment. In patients with multiple organ failure, however, one-tenth of the usual dose without an initial bolus is recommended, depending on hepatic function [24].

Different argatroban dosing regimens have been described for different RRT modalities. A proposed dose in chronic haemodialysis patients is a $250 \mu \mathrm{g} / \mathrm{kg}$ bolus followed by continuous infusion of $2 \mu \mathrm{g} / \mathrm{kg} /$ minute [25]. In ICU patients treated with CRRT, it is recommended to administer a loading dose of $100 \mu \mathrm{g} / \mathrm{kg}$ argatroban followed by a maintenance infusion rate $(\mu \mathrm{g} / \mathrm{kg} /$ minute $)$ that is adjusted for severity of illness (measured by either $2.15-0.06 \times$ Acute Physiology and Chronic Health Evaluation II score, or by $2.06-0.03 \times$ Simplified Acute Physiology Score II) and liver function, assessed by the indocyanine green disappearance rate $(-0.35+0.08 \times$ indocyanine green disappearance rate) [26]. For ICU patients treated with predilution intermittent venovenous haemodialysis, recommendations are a loading dose of $75 \mu \mathrm{g} / \mathrm{kg}$ followed by a continuous infusion of 0.4 to $0.6 \mu \mathrm{g} / \mathrm{kg} /$ minute until 20 minutes before termination of RRT [27].

Despite clinical use of argatroban in RRT, it should be mentioned that this is an off-label use for this drug.

Fondaparinux is a synthetic heparin analogue that can be used in patients with heparin-induced thrombocytopaenia type II. In the absence of renal function, a single intravenous dose of $2.5 \mathrm{mg}$ can maintain dialysis circuit patency provided that low-flux membranes are used [28]. Owing to its renal clearance, therapeutic anti-factor $\mathrm{Xa}$ activity is still demonstrated 48 hours after administration of $2.5 \mathrm{mg}$ fondaparinux. Removal of fondaparinux is enhanced by the use of high-flux membranes. In ICU patients, caution is recommended for this anticoagulant considering its long half-life and the high bleeding risk, and/or the frequent need for surgical intervention or invasive procedures. Also, heparin-induced thrombocytopaenia is an off-label indication for fondaparinux.

Lepirudin, or recombinant hirudin, is a direct thrombin inhibitor and can also be used in patients with heparininduced thrombocytopaenia type II. In dialysis patients, a single intravenous dose of $0.08 \mathrm{mg} / \mathrm{kg}$ is recommended [29]. Because of its renal clearance, this dose results in sustained anticoagulation. Dialyser clearance depends on the membrane characteristics. High-flux membranes allow filtration of lepirudin, with the highest sieving coefficient for polysulfone (0.97) and lesser sieving coefficients for polymethylmethacrylate and polyarylethersulfone $(0.75$ and 0.73 , respectively). Low-flux membranes do not filter lepirudin [30]. Dependent on the dialysis frequency, the dialysis membrane, and the activated partial thromboplastin time, measured before the start of the dialysis session, a reduced dose should be used from the second dialysis. Because of its prolonged half-life (52 hours), lepirudin is not an anticoagulant of choice in the intensive care patient with AKI.

\section{Patients with severe haemodynamic instability}

Haemodynamically unstable patients should be treated carefully, which can be achieved either by CVVH(D), sustained low-efficiency daily dialysis or continuous HD. In many haemodynamically unstable patients, $\mathrm{HD}$ can be performed when specific precautions are taken [31,32]. These precautions include: less aggressive ultrafiltration, increasing the treatment time in CRRT and daily 
treatment in intermittent HD, eventually using blood volume measurements to guide ultrafiltration; increasing dialysate sodium and calcium concentrations to respectively $145 \mathrm{mmol} / \mathrm{l}$ and $1.5 \mathrm{mmol} / \mathrm{l}$; adapting the dialysate temperature to obtain isothermic dialysis; connecting afferent and efferent bloodlines simultaneously at the start of the procedure; using low blood flow $(<150 \mathrm{ml} /$ minute) and low dialysate flows; using biocompatible membranes; and using (ultra)pure water [31].

An argument in favour of CRRT in haemodynamically unstable patients is that solute control is more constant. This factor may be of particular benefit in patients with severe lactic acidosis, where RRT may help to stabilise the haemodynamic status by correction of blood $\mathrm{pH}$. In patients with severe lactic acidosis, intermittent therapy will only offer a temporal improvement of blood $\mathrm{pH}-$ between treatments there will be recurrent acidosis, with its untoward haemodynamic consequences.

In summary, patients with severe haemodynamic instability are best treated with CRRT in order to allow removal of extravascular fluid and to maintain a stable blood $\mathrm{pH}$.

A more elaborate discussion on the choice between CRRT and HD is presented in another publication in this topic series [33].

\section{Patients with intracranial hypertension or cerebral oedema}

Patients with cerebral oedema or intracranial hypertension have decreased or absent autoregulation of cerebral blood flow. A decrease in systemic blood pressure, as may occur during RRT, will therefore lead to decreased cerebral blood flow and to cerebral ischaemia, which will consequently lead to more oedema [34]. Continuous arteriovenous haemofiltration has been proven to better maintain cerebral blood flow in patients with acute liver failure and cerebral oedema compared with intermittent dialysis $[35,36]$. These findings have been extrapolated to treatment recommendations for patients with other causes of cerebral oedema and to newer modalities of CRRT such as CVVH or CVVHD [37,38].

Another argument in favour of a low efficient CRRT is that this therapy will seldom be complicated with acute and important tonicity changes of the systemic circulation. Because intermittent HD is a very efficient RRT modality, these changes may occur after a session of HD. A decrease in serum osmolality will subsequently lead to water uptake by the cells, and to development of cellular oedema [39]. Intracranial pressure may therefore increase after HD.

If a patient is also at increased risk for intracranial haemorrhage, such as after traumatic brain injury, RRT should be administered without anticoagulation or with regional citrate anticoagulation. Theoretically, PD can be considered as an alternative. Concerns on this modality are the efficacy and the effects on intra-abdominal pressure. The intra-abdominal pressure may increase secondary to infusion of PD fluid in the abdominal cavity, which may have diverse effects on intracranial pressure and cerebral perfusion [40,41]. Increased abdominal pressure may translate into increased intracranial pressure. Further, intra-abdominal hypertension may also decrease systemic preload and increase afterload, leading to lower blood pressure and decreased cerebral perfusion pressure.

\section{Patients with hyponatraemia}

When chronic hyponatraemia is corrected rapidly, patients may develop osmotic demyelination syndrome $[42,43]$, a condition with most irreversible brain damage. Therefore, in asymptomatic patients with chronic hyponatraemia, the sodium concentration should be increased slowly, with a maximum increase of 10 to $12 \mathrm{mmol} / \mathrm{l}$ during the first 24 hours and of $18 \mathrm{mmol} / \mathrm{l}$ during the first 48 hours of treatment [44]. High serum urea concentration may protect the brain against the development of osmotic demyelination [45,46]. An explanation for this may be the slow diffusion of urea over the blood-brain barrier. Dialysis will decrease serum urea rapidly, but urea that has accumulated in brain cells will decrease only slowly. This difference will create a blood-brain gradient of urea, and will lead to accumulation of water in brain cells and a slower decline of cell volume, which is the mechanism that leads to osmotic demyelination. Low-efficiency RRT such as $\mathrm{CVVH}$ is recommended in these patients.

Some authors have recommended the use of replacement fluid with reduced sodium concentration. This can be established by adding sterile water to the replacement fluid bag [47]. Diluting replacement fluid will also result in decreased potassium and bicarbonate concentrations, and therefore may induce hypokalaemia and acidosis. These patients therefore need frequent follow-up of sodium and potassium concentrations and blood $\mathrm{pH}$. During treatment, increasing plasma sodium concentrations may require less diluted replacement fluid; patients may also have need for additional potassium or bicarbonate infusion. Because this procedure is potentially error prone, and may lead to contamination of sterile replacement fluid, an alternative strategy is intravenous infusion of hypotonic fluid (for example, $5 \%$ glucose).

\section{Patients with high serum urea concentration}

When serum urea is high (typically $>175 \mathrm{mg} / \mathrm{dl}$ ) patients are at risk for developing dialysis disequilibrium syndrome, a neurological condition characterised by nausea and headache. The exact mechanism of dialysis disequilibrium is uncertain. A sudden decrease of serum 
osmolality and slower decrease of (brain) cell osmolality with resultant increase of cellular water content is the most probable cause. A change in intracellular $\mathrm{pH}$ and accumulation of organic osmolites are also mentioned as a possible cause for this condition. Preventive measures include initiation RRT with ultrafiltration followed by dialysis, which will increase plasma osmolarity and so prevent development of cerebral oedema and dialysis disequilibrium. Decreasing the dose of dialysis will also prevent important changes of urea concentration, and so prevent dialysis disequilibrium. This can be achieved by shortening the first RRT session when intermittent modalities are used (2 hours), decreasing blood flow ( $<200 \mathrm{ml} /$ minute), using a small less efficient dialyser, or using low-dose CVVH (for example, ultrafiltration rate $<20 \mathrm{ml} / \mathrm{kg} /$ hour). A urea reduction ratio of 0.4 to 0.45 or a urea clearance over time of the dialysis session corrected for volume of distribution (Kt/V) of 0.6 to 0.7 has been proposed. Administration of osmotic agents such as mannitol (1 $\mathrm{g} / \mathrm{kg}$ intravenously per dialysis session) may also be of help. Finally, an increased dialysate sodium concentration (143 to $146 \mathrm{mmol} / \mathrm{l}$ ) is also recommended in patients at risk [48-50].

\section{Patients with acute or acute on chronic liver failure}

There are several aspects that deserve special attention in patients with liver failure and AKI.

\section{Encephalopathy and cerebral oedema}

Patients with acute liver failure and encephalopathy are very likely to have cerebral oedema, especially when the time between occurrence of jaundice and encephalopathy is short; for example, as in fulminant liver failure, defined by a time delay between icterus and encephalopathy of less than 2 weeks $[37,51]$. These patients are at increased risk for increased intracranial pressure and brain stem herniation. One should therefore apply the principles for prevention of deterioration of intracranial pressure as described above. In summary, CRRT with special attention for haemodynamic stability and maintenance of cerebral perfusion pressure is warranted.

\section{Hyponatraemia}

Patients with liver failure often experience chronic hyponatraemia. Hence, special attention should be given to a slow increase of serum sodium, as discussed above.

\section{Hepatorenal syndrome}

Patients with acute and acute on chronic liver failure may develop AKI as a consequence of hepatorenal syndrome. Especially in patients with acute on chronic liver failure this is an end stage of the process of water retention and increased catecholamine stress, characterised by hyponatraemia and ascites [52].
A small prospective randomised study suggests that treatment with artificial liver support may improve survival in these patients [53]. This study was underpowered ( $n=13$ patients), however, and the control population was not treated with vasopressin analogues, which is currently the standard of care. A large prospective randomised study comparing the standard of care for liver dialysis with that of the Prometheus liver dialysis system (Fresenius Medical Care, Bad Homburg, Germany) in patients with acute on chronic liver failure recently found in subanalysis that patients with hepatorenal syndrome treated with Prometheus liver dialysis had better survival [54]. This study is currently only presented as an abstract, so we can only discuss preliminary results.

There are no data that support the use of one specific RRT modality above another for hepatorenal syndrome, although generally less aggressive modalities such as sustained low-efficiency daily dialysis or CRRT will be used most.

\section{Coagulation abnormalities}

Patients with liver failure have decreased production of coagulation factors II, V, VII, IX, X and XI, thrombocytopaenia and decreased thrombocyte function $[55,56]$. This will lead to decreased coagulation. Many patients with severe liver failure can therefore undergo RRT without anticoagulation. However, decreased production of protein $\mathrm{C}$, protein $\mathrm{S}$ and antithrombin III, increased concentrations of factor VIII, von Willebrand factor and heparin cofactor II, and a decreased concentration of plasminogen will lead to increased coagulation, despite abnormal coagulation tests. Coagulation tests can therefore be misleading and, despite abnormal tests, filter clotting may occur. Monitoring the coagulation status with functional haemostasis monitoring devices such as thromboelastography or Sonoclot (Sienco Inc., Arvada, Colorado, USA), which measure the individual contribution of coagulation by platelets and coagulation factors, and fibrinolysis may be of help to better understand the coagulation status of these patients.

\section{Patients with severe lactic acidosis}

The treatment for lactic acidosis should be aimed at correcting the cause. However, as severe acidosis may in itself lead to profound systemic hypotension, RRT is sometimes used as a bridge until correction of the underlying cause, especially in patents who also have AKI [57]. RRT may correct blood $\mathrm{pH}$, by removing lactic acid and through administration of bicarbonate from the dialysate. Continuous modalities are preferred to prevent intradialytic rebound, and dialysis is more efficient in removing small molecules as lactate [58,59]. 


\section{Patients with congestive heart failure}

Patients with decompensated heart failure and diuretic resistance, without AKI, can benefit from isolated ultrafiltration $[60,61]$. When these patients are haemodynamically unstable, the ultrafiltration rate should be limited by increasing the treatment time. This limitation can be achieved by CRRT or hybrid therapy. PD is also used for fluid removal in patients with congestive heart failure and ESKD. However, fluid removal is less predictable compared with extracorporeal ultrafiltration $[62,63]$.

Special attention should be given to patients with congestive heart failure and (chronic) hyponatraemia (see the discussion on hyponatraemia above).

\section{Patients with burn injury}

On average, $3 \%$ of patients with severe burn injury are treated with RRT for AKI [64]. Patients with burn injury and AKI often have large wounds and repetitive surgical interventions with increased risk for bleeding.

Another issue in burn patients is accumulation of iodine. Burn patients treated with topical povidoneiodine may have elevated iodine concentrations, secondary to increased absorption in combination with hampered renal excretion. This can lead to metabolic acidosis, AKI, and heart conduction abnormalities, eventually leading to heart block. The molecular weight of iodine is 253; hence the dialyser clearance during highflux dialysis is comparable with that of small solutes such as urea. Intercompartmental clearance is low, however, so long treatment times are mandatory [65]. Protracted high-flux haemodialysis or haemodiafiltration, with high blood and dialysate flow, is therefore the treatment of choice to remove iodine.

\section{Patients with accidental hypothermia}

Consensus exists about cardiopulmonary bypass as the treatment of choice in cases of severe accidental hypothermia with cardiac arrest. In settings where cardiopulmonary bypass is not available, or in haemodynamically stable patients, HD is a valuable alternative [66]. Setting dialysate flow and temperature to their maximum optimises the efficiency of warming. Blood flow and the membrane surface should also be optimised. HD can be started without exogenous anticoagulation because hypothermia is associated with coagulopathy.

\section{Patients with intoxications}

The use of RRT in the treatment of intoxicated patients has decreased over recent years. Reasons for this decline are diverse. Some intoxications, such as with paraquat and theophyllin, are nowadays less frequent in the western world. Other intoxications, such as with methanol and ethylene glycol, are often treated with fomepizole. At present, the most frequently encountered intoxications treated with RRT are caused by lithium, methanol, ethylene glycol and iodine. Rare intoxications that should in special indications be treated with haemodialysis include valproic acid, isoniazid and metformin [67]. The mainstay for treatment of salicylate intoxication remains alkalinisation of blood and urine. In patients with severe salicylate intoxication and in patients presenting with severe fluid overload and/or pulmonary or cerebral oedema, however, HD should be used to effectively remove salicylate from blood $[68,69]$.

With the introduction of high-flux membranes and haemodiafiltration, haemoperfusion with charcoal cartridges has lost importance.

The lack of residual endogenous clearance, sometimes caused by the intoxication itself, will accelerate the decision to start dialysis. Examples include AKI in patients with lithium, iodine or ethylene glycol intoxications. If the molecular weight of a toxin is low and protein binding is limited, dialyser clearance is expected to be high. This is a prerequisite for efficient removal. The body clearance depends on the compartmental behaviour. If the distribution is multicompartmental, with slow equilibration between the different compartments, rebound can ensue. In these cases, long dialysis times are necessary. Because of this latter reason and because of the availability of alternative treatment (digoxin-specific Fab fragments), digoxin intoxications are seldom treated by haemodialysis.

Our preference is to apply haemodialysis (mostly high flux) with high blood flow (250 to $300 \mathrm{ml} /$ minute) and high dialysate flow $(500 \mathrm{ml} / \mathrm{minute})$ and a long treatment time or even continuously in order to optimise both dialyser and body clearance. For larger solutes, protracted or continuous online haemodiafiltration is more efficient. CVVH or CVVHD results in much less dialyser clearance because of absent or limited dialysate flow. Patients with lithium intoxication without renal failure should preferably not be treated with a single-pass batch system, as premature mixing of dialysate has been documented in the absence of uraemic solutes [70]. In these patients, haemodialysis with a conventional haemodialysis machine is recommended.

\section{Chronic haemodialysis patients admitted to the ICU}

Chronic haemodialysis patients represent a minority of ICU patients. In a tertiary care centre in the USA, 3.7\% of ICU patients were chronic haemodialysis patients [71]. Other studies found that 11 to $12 \%$ of all patients treated with RRT in the ICU are chronic dialysis patients [72,73]. The main reasons for ICU admission are sepsis and cardiovascular complications, which are comparable with AKI patients [72,73]. Instead of the regular outpatient 
dialysis schedule of 4 hours of dialysis three times weekly, RRT during the ICU stay should be adapted towards the current needs of the patient. Daily, protracted dialysis can easily be performed through the arteriovenous fistula. Staff should be extremely vigilant in keeping this arteriovenous fistula patent. They should therefore be advised against using the arm with the arteriovenous fistula for blood sampling, arterial line insertion or noninvasive blood pressure measurement. Needling of this arteriovenous fistula should only be performed by an experienced dialysis nurse. A temporary dialysis catheter is preferred when a continuous technique is applied.

\section{Renal replacement therapy during surgery}

Occasionally, haemodialysis is performed during surgery. Because liver transplantation in patients with renal impairment can be associated with severe hyperkalaemia, especially during reperfusion, intraoperative dialysis should be considered. Unstable patients with acidosis and persistent electrolyte disturbances may also benefit from a continuation of the dialysis in the operation room. Special attention should be paid to the temperature of the dialysate, to avoid cooling of the patient. If no water treatment is available in the operation room, haemodialysis can be performed with a single-pass batch system. Anticoagulation is mostly contraindicated, or in the case of liver transplantation is not needed. If necessary, a heparin-coated membrane can be used [74]. During liver transplantation, citrate may accumulate when regional citrate anticoagulation is used. The citrate load is often already elevated in these patients due to the administration of fresh frozen plasma and packed cells. We therefore do not recommend citrate anticoagulation in these patients.

\section{Extracorporeal therapy in sepsis} Continuous venovenous haemofiltration

Two prospective randomised studies evaluated the use of standard CVVH compared with the standard of care in patients with severe sepsis $[75,76]$. The rationale was that inflammatory mediators were removed at a constant rate in the CVVH intervention group, and that the inflammatory process could therefore be halted. Neither study could demonstrate that CVVH led to decreased serum concentrations of mediators, or to improvement of organ dysfunction. In fact, the most recent study was discontinued after an interim analysis on 76 patients demonstrated more organ dysfunction and more severe organ dysfunction in patients randomised to $\mathrm{CVVH}$ compared with the standard of care [76].

\section{High-volume haemofiltration}

Observational data by Ratanarat and colleagues and by Honore and colleagues demonstrated that short-term high-volume haemofiltration -6 to 8 hours of $\mathrm{CVVH}$ at $85 \mathrm{ml} / \mathrm{kg} /$ hour followed by 16 to 18 hours of CVVH at $35 \mathrm{ml} / \mathrm{kg} /$ hour [77], and ultrafiltration of $35 \mathrm{l}$ during a 4-hour period followed by conventional CVVH [78] was associated with better outcomes than compared with historic controls $[77,78]$. In the High Volume on Intensive Care (IVOIRE) study, septic study patients were randomised to high-volume haemofiltration $(70 \mathrm{ml} / \mathrm{kg} /$ hour for 96 hours) or to standard-dose CVVH (35 ml/kg/hour). The study was recently stopped after interim analysis, but was not yet published at the time of this review. The results will inform us on the exact place of this technique for treatment of sepsis patients.

\section{Polymyxin-B haemoperfusion}

Polymyxin-B bound to a membrane is a compound that efficiently binds endotoxin, a component released from the cell membrane of Gram-negative bacteria. Endotoxin is a crucial component in the inflammatory cascade following Gram-negative infection. Several smaller studies that were bundled in a meta-analysis and a recent small prospective randomised study in patients with intraabdominal sepsis demonstrated that binding endotoxin with polymyxin-B haemoperfusion may improve haemodynamics and organ function at 72 hours, and may improve short-term (28-day) mortality in sepsis patients $[79,80]$. These results are promising, but the dataset is still too small to adopt this therapy in routine practice.

\section{Coupled plasma filtration and absorption combined with haemodialysis.}

Coupled plasma filtration and absorption also targets diminishing the inflammatory process, by removing inflammatory mediators through absorption. For this technique, blood is filtered by a plasma filter. Plasma that is produced by the plasma filter is run through an absorption filter, reinfused into the circuit, and subsequently filtered by a high-permeable polysulfone haemofilter. Results from a small pilot crossover study in 10 patients with severe septic shock demonstrated that this technique improved haemodynamics during the 10-hour plasma filtration and absorption session compared with CVVHDF [81]. Responsiveness of white blood cells to stimulation with lipopolysaccharide was also normalised after treatment with coupled plasma filtration and absorption. A prospective randomised study on this technique was concluded in Italy recently, but the results have not yet been published.

\section{Conclusions}

Especially in ICU patients who have severe AKI, treatment with RRT requires balancing the pros and cons of different options and modalities. Special groups of ICU patients that deserve extra consideration are, for 
example, patients with coagulation abnormalities or with increased risk for bleeding, such as after surgery, patients with severe haemodynamic instability, liver failure patients and patients with hyponatraemia. Exact and specific guidelines for RRT in these patients are not available for most clinical situations.

\section{Abbreviations}

$\mathrm{AKI}$, acute kidney injury; $\mathrm{CVVH}$, continuous venovenous haemofiltration; CVVHD, continuous venovenous haemodialysis; CVVHDF, continuous venovenous haemodiafiltration; CRRT, continuous renal replacement therapy; ESKD, end-stage kidney disease; HD, haemodialysis; PD, peritoneal dialysis; RRT, renal replacement therapy.

\section{Competing interests}

AD declares that she has no competing interests. EAJH advised both Gambro and Fresenius in an advisary board, and received a fee for this.

\section{Author details}

'Department of Intensive Care Medicine, ICU, 2-K12C, Ghent University Hospital, De Pintelaan 185, 9000 Gent, Belgium. ${ }^{2}$ Research Foundation Flanders, Ghent

University Hospital, De Pintelaan 185, 9000 Gent, Belgium. ${ }^{3}$ Nephrology Section, Ghent University Hospital, De Pintelaan 185, 9000 Gent, Belgium.

Published: 19 January 2012

\section{References}

1. Hoste EAJ, Schurgers M: Epidemiology of AKI: how big is the problem? Crit Care Med 2008, 36:S1-S4.

2. Xue JL, Daniels F, Star RA, Kimmel PL, Eggers PW, Molitoris BA, Himmelfarb J, Collins AJ: Incidence and mortality of acute renal failure in Medicare beneficiaries, 1992 to 2001. J Am Soc Nephrol 2006, 17:1135-1142

3. Waikar SS, Curhan GC, Wald R, McCarthy EP, Chertow GM: Declining mortality in patients with acute renal failure, 1988 to 2002. J Am SoC Nephrol 2006, 17:1143-1150.

4. Kielstein JT, Kretschmer U, Ernst T, Hafer C, Bahr MJ, Haller H, Fliser D: Efficacy and cardiovascular tolerability of extended dialysis in critically ill patients: a randomized controlled study. Am J Kidney Dis 2004, 43:342-349.

5. Phu NH, Hien TT, Mai NT, Chau TT, Chuong LV, Loc PP, Winearls C, Farrar J, White N, Day N: Hemofiltration and peritoneal dialysis in infectionassociated acute renal failure in Vietnam. N Engl J Med 2002, 347:895-902.

6. Gabriel DP, Caramori JT, Martim LC, Barretti P, Balbi AL: High volume peritoneal dialysis vs daily hemodialysis: a randomized, controlled trial in patients with acute kidney injury. Kidney Int Supp/ 2008, 73:S87-S93.

7. Gabriel DP, Caramori JT, Martin LC, Barretti P, Balbi AL: Continuous peritoneal dialysis compared with daily hemodialysis in patients with acute kidney injury. Perit Dial Int 2009, 29(Suppl 2):S62-S71.

8. George J, Varma S, Kumar S, Thomas J, Gopi S, Pisharody R: Comparative study of continuous venovenous hemodiafiltration and peritoneal dialysis in critically ill patients with acute kidney injury: a pilot study. Perit Dial Int 2011, 31:422-429.

9. Ricci Z, Ronco C, D'Amico G, De Felice R, Rossi S, Bolgan I, Bonello M, Zamperetti N, Petras D, Salvatori G, Dan M, Piccinni P: Practice patterns in the management of acute renal failure in the critically ill patient: an international survey. Nephrol Dial Transplant 2006, 21:690-696.

10. Pinnick RV, Wiegmann TB, Diederich DA: Regional citrate anticoagulation for hemodialysis in the patient at high risk for bleeding. N Engl J Med 1983, 308:258-261.

11. Davenport A, Tolwani A: Citrate anticoagulation for continuous renal replacement therapy (CRRT) in patients with acute kidney injury admitted to the intensive care unit. NDT Plus 2009, 2:439-447.

12. Oudemans-van Straaten HM: Citrate anticoagulation for continuous renal replacement therapy in the critically ill. Blood Purif 2010, 29:191-196.

13. Bagshaw SM, Laupland KB, Boiteau PJ, Godinez-Luna T: Is regional citrate superior to systemic heparin anticoagulation for continuous renal replacement therapy? A prospective observational study in an adult regional critical care system. J Crit Care 2005, 20:155-161.

14. Monchi M, Berghmans D, Ledoux D, Canivet JL, Dubois B, Damas P: Citrate vs. heparin for anticoagulation in continuous venovenous hemofiltration: a prospective randomized study. Intensive Care Med 2004, 30:260-265.
15. Kutsogiannis DJ, Gibney RT, Stollery D, Gao J: Regional citrate versus systemic heparin anticoagulation for continuous renal replacement in critically ill patients. Kidney Int 2005, 67:2361-2367.

16. Oudemans-van Straaten HM, Bosman RJ, Koopmans M, van der Voort PH, Wester JP, van der Spoel Jl, Dijksman LM, Zandstra DF: Citrate anticoagulation for continuous venovenous hemofiltration. Crit Care Med 2009, 37:545-552.

17. Hetzel GR, Schmitz M, Wissing H, Ries W, Schott G, Heering PJ, Isgro F, Kribben A, Himmele R, Grabensee B: Regional citrate versus systemic heparin for anticoagulation in critically ill patients on continuous venovenous haemofiltration: a prospective randomized multicentre trial. Nephrol Dial Transplant 2011, 26:232-239.

18. Darby JPJ, Sorensen RJ, O'Brien TF, Teschan PE: Efficient heparin assay for monitoring regional heparinization and hemodialysis. N Engl J Med 1960, 262:654-657.

19. Teschan P, Baxter C, O'Brian T, Freyhof J, Hall W: Prophylactic hemodialysis in the treatment of actue renal failure. Ann Intern Med 1960, 53:992-1016.

20. European Best Practice Guidelines Expert Group on Hemodialysis, European Renal Association: European Best Practice Guidelines. Section V. Chronic intermittent haemodialysis and prevention of clotting in the extracorporal system. Nephrol Dial Transplant 2002, 17(Suppl 7):63-71.

21. Kozek-Langenecker SA, Spiss CK, Gamsjager T, Domenig C, Zimpfer M: Anticoagulation with prostaglandins and unfractionated heparin during continuous venovenous haemofiltration: a randomized controlled trial. Wien Klin Wochenschr 2002, 114:96-101.

22. Davenport A, Will EJ, Davison AM: Comparison of the use of standard heparin and prostacyclin anticoagulation in spontaneous and pumpdriven extracorporeal circuits in patients with combined acute renal and hepatic failure. Nephron 1994, 66:431-437.

23. Davenport A, Will EJ, Davison AM: The effect of prostacyclin on intracranial pressure in patients with acute hepatic and renal failure. Clin Nephrol 1991 35:151-157.

24. Beiderlinden M, Treschan TA, Gorlinger K, Peters J: Argatroban anticoagulation in critically ill patients. Ann Pharmacother 2007, 41:749-754

25. Murray PT, Reddy BV, Grossman EJ, Hammes MS, Trevino S, Ferrell J, Tang I, Hursting MJ, Shamp TR, Swan SK: A prospective comparison of three argatroban treatment regimens during hemodialysis in end-stage renal disease. Kidney Int 2004, 66:2446-2453.

26. Link A, Girndt M, Selejan S, Mathes A, Bohm M, Rensing H: Argatroban for anticoagulation in continuous renal replacement therapy. Crit Care Med 2009, 37:105-110.

27. Sun X, Chen Y, Xiao Q, Wang Y, Zhou J, Ma Z, Xiang J, Chen X: Effects of argatroban as an anticoagulant for intermittent veno-venous hemofiltration (IVVH) in patients at high risk of bleeding. Nephrol Dial Transplant 2011, 26:2954-2959.

28. Sombolos KI, Fragia TK, Gionanlis LC, Veneti PE, Bamichas GI, Fragidis SK, Georgoulis IE, Natse TA: Use of fondaparinux as an anticoagulant during hemodialysis: a preliminary study. Int J Clin Pharmacol Ther 2008, 46:198-203.

29. Vanholder R, Dhondt A: Recombinant hirudin: clinical pharmacology and potential applications in nephrology. BioDrugs 1999, 11:417-429.

30. Benz K, Nauck MA, Bohler J, Fischer KG: Hemofiltration of recombinant hirudin by different hemodialyzer membranes: implications for clinical use. Clin J Am Soc Nephrol 2007, 2:470-476.

31. Schortgen F, Soubrier N, Delclaux C, Thuong M, Girou E, Brun-Buisson C, Lemaire F, Brochard L: Hemodynamic tolerance of intermittent hemodialysis in critically ill patients. Usefulness of practice guidelines. Am J Respir Crit Care Med 2000, 162:197-202.

32. Vinsonneau C, Camus C, Combes A, Costa de Beauregard MA, Klouche K, Boulain T, Pallot J-L, Chiche J-D, Taupin P, Landais P: Continuous venovenous haemodiafiltration versus intermittent haemodialysis for acute renal failure in patients with multiple-organ dysfunction syndrome: a multicentre randomised trial. The Lancet 2006, 368:379-385

33. Vanholder R, Van Biesen W, Hoste E, Lameire N: Pro/Con debate: Continuous versus intermittent dialysisfor acute kindey injury: a never-ending story yet approaching the finish? Crit Care 2011, 15:204.

34. Davenport A, Will EJ, Losowsky MS: Rebound surges of intracranial pressure as a consequence of forced ultrafiltration used to control intracranial pressure in patients with severe hepatorenal failure. Am J Kidney Dis 1989, 14:516-519.

35. Davenport A, Will EJ, Davidson AM: Improved cardiovascular stability 
during continuous modes of renal replacement therapy in critically ill patients with acute hepatic and renal failure. Crit Care Med 1993, 21:328-338.

36. Davenport A, Will EJ, Losowsky MS, Swindells S: Continuous arteriovenous haemofiltration in patients with hepatic encephalopathy and renal failure [case report]. BrMed J (Clin Res Ed) 1987, 295:1028.

37. Stravitz RT, Kramer AH, Davern T, Shaikh AO, Caldwell SH, Mehta RL, Blei AT, Fontana RJ, McGuire BM, Rossaro L, Smith AD, Lee WM: Intensive care of patients with acute liver failure: recommendations of the U.S. Acute Liver Failure Study Group. Crit Care Med 2007, 35:2498-2508.

38. Davenport A: Anticoagulation options for patients with heparin-induced thrombocytopenia requiring renal support in the intensive care unit. Contrib Nephrol 2007, 156:259-266.

39. Davenport A: Practical guidance for dialyzing a hemodialysis patient following acute brain injury. Hemodial Int 2008, 12:307-312.

40. De laet I, Citerio G, Malbrain ML: The influence of intraabdominal hypertension on the central nervous system: current insights and clinical recommendations, is it all in the head? Acta Clin Belg Supp/ 2007, 1:89-97.

41. Hunter JD, Damani Z: Intra-abdominal hypertension and the abdominal compartment syndrome. Anaesthesia 2004, 59:899-907.

42. Huang WY, Weng WC, Peng TI, Ro LS, Yang CW, Chen KH: Central pontine and extrapontine myelinolysis after rapid correction of hyponatremia by hemodialysis in a uremic patient. Ren Fail 2007, 29:635-638.

43. Tarhan NC, Agildere AM, Benli US, Ozdemir FN, Aytekin C, Can U: Osmotic demyelination syndrome in end-stage renal disease after recent hemodialysis: MRI of the brain. AJR Am J Roentgenol 2004, 182:809-816.

44. Verbalis JG, Goldsmith SR, Greenberg A, Schrier RW, Sterns RH: Hyponatremia treatment guidelines 2007: expert panel recommendations. Am J Med 2007, 120:S1-S21.

45. Oo TN, Smith CL, Swan SK: Does uremia protect against the demyelination associated with correction of hyponatremia during hemodialysis? A case report and literature review. Semin Dial 2003, 16:68-71.

46. Soupart A, Penninckx R, Stenuit A, Decaux G: Azotemia ( 48 h) decreases the risk of brain damage in rats after correction of chronic hyponatremia. Brain Res 2000, 852:167-172.

47. Ostermann M, Dickie H, Tovey L, Treacher D: Management of sodium disorders during continuous haemofiltration. Crit Care 2010, 14:418.

48. Arieff Al: Dialysis disequilibrium syndrome: current concepts on pathogenesis and prevention. Kidney Int 1994, 45:629-635.

49. Patel N, Dalal P, Panesar M: Dialysis disequilibrium syndrome: a narrative review. Semin Dial 2008, 21:493-498.

50. Rodrigo F, Shideman J, McHugh R, Buselmeier T, Kjellstrand C: Osmolality changes during hemodialysis. Natural history, clinical correlations, and influence of dialysate glucose and intravenous mannitol. Ann Intern Med 1977, 86:554-561.

51. Trotter JF: Practical management of acute liver failure in the intensive care unit. Curr Opin Crit Care 2009, 15:163-167.

52. Gines P, Schrier RW: Renal failure in cirrhosis. N Engl J Med 2009 , 361:1279-1290.

53. Mitzner SR, Stange J, Klammt S, Risler T, Erley CM, Bader BD, Berger ED, Lauchart W, Peszynski P, Freytag J: Improvement of hepatorenal syndrome with extracorporeal albumin dialysis MARS: results of a prospective, randomized, controlled clinical trial. Liver Transp/ 2000, 6:277-286.

54. Rifai K, Kribben A, Gerken G, Haag S, Herget-Rosenthal S, Treichel U, Betz C, Sarrazin C, Van Vlierberghe H, Hoste E, Escorsell A, Gines P, Hafer C, Schuchmann M, Galle PR, Bernardi M, Caraceni P, Àbeles R, Frieder-Berr Knotek M, Kozik-Jaromin J: A prospective randomized controlled multicenter study of extracorporeal liver support by fractionated plasma separation and absorption (Prometheus (R)) in patients with acute-onchronic liver failure (HELIOS study) [abstract]. Hepatology 2010, 52:333A.

55. Trotter JF: Coagulation abnormalities in patients who have liver disease. Clin Liver Dis 2006, 10:665-678, x-xi.

56. Wada H, Usui M, Sakuragawa N: Hemostatic abnormalities and liver diseases. Semin Thromb Hemost 2008, 34:772-778.

57. Peters N, Jay N, Barraud D, Cravoisy A, Nace L, Bollaert PE, Gibot S: Metforminassociated lactic acidosis in an intensive care unit. Crit Care 2008, 12:R149.

58. Levraut J, Ciebiera JP, Jambou P, Ichai C, Labib Y, Grimaud D: Effect of continuous venovenous hemofiltration with dialysis on lactate clearance in critically ill patients. Crit Care Med 1997, 25:58-62

59. Vuylsteke S, Dhondt A, Danneels C, De Waele J, Blot S, Hoste E: Initiation of renal replacement therapy in patients with acute kidney injury and severe lactic acidosis [abstract]. Critical Care 2008, 12(Suppl 2):P479

60. Costanzo MR, Saltzberg M, O'Sullivan J, Sobotka P: Early ultrafiltration in patients with decompensated heart failure and diuretic resistance. J Am Coll Cardiol 2005, 46:2047-2051.

61. Costanzo MR, Ronco C: Extracorporeal fluid removal in heart failure patients. Contrib Nephrol 2010, 165:236-243.

62. Sanchez JE, Ortega T, Rodriguez C, Diaz-Molina B, Martin M, Garcia-Cueto C, Vidau P, Gago E, Ortega F: Efficacy of peritoneal ultrafiltration in the treatment of refractory congestive heart failure. Nephrol Dial Transplant 2010, 25:605-610.

63. Cnossen N, Kooman JP, Konings CJ, van Dantzig JM, van der Sande FM, Leunissen K: Peritoneal dialysis in patients with congestive heart failure. Nephrol Dial Transplant 2006, 21(Suppl 2):ii63-ii66.

64. Brusselaers N, Monstrey S, Colpaert K, Decruyenaere J, Blot SI, Hoste EA: Outcome of acute kidney injury in severe burns: a systematic review and meta-analysis. Intensive Care Med 2010, 36:915-925.

65. Eloot S, Dhondt A, Hoste E, Verstraete A, De Waele J, Colpaert K, Hoeksema H, Tromp F, Vanholder R: How to remove accumulated iodine in burn-injured patients. Nephrol Dial Transplant 2010, 25:1614-1620.

66. Caluwe R, Vanholder R, Dhondt A: Hemodialysis as a treatment of severe accidental hypothermia. Artif Organs 2010, 34:237-239.

67. Temmerman W, Dhondt A, Vandewoude K: Acute isoniazid intoxication: seizures, acidosis and coma. Acta Clin Belg 1999, 54:211-216.

68. Cohen DL, Post J, Ferroggiaro AA, Perrone J, Foster MH: Chronic salicylism resulting in noncardiogenic pulmonary edema requiring hemodialysis. Am J Kidney Dis 2000, 36:E20.

69. Glisson JK, Vesa TS, Bowling MR: Current management of salicylate-induced pulmonary edema. South Med J 2011, 104:225-232.

70. Dhondt A, Verstraete A, Vandewoude K, Segers H, Eloot S, Decruyenaere J, Vanholder R: Efficiency of the Genius batch hemodialysis system with low serum solute concentrations: the case of lithium intoxication therapy. Am J Kidney Dis 2005, 46:e95-e99.

71. Clermont G, Acker CG, Angus DC, Sirio CA, Pinsky MR, Johnson JP: Renal failure in the ICU: comparison of the impact of acute renal failure and end-stage renal disease on ICU outcomes. Kidney Int 2002, 62:986-996.

72. Uchino S, Morimatsu H, Bellomo R, Silvester W, Cole L: End-stage renal failure patients requiring renal replacement therapy in the intensive care unit: incidence, clinical features, and outcome. Blood Purif 2003, 21:170-175

73. Rocha E, Soares M, Valente C, Nogueira L, Bonomo HJ, Godinho M, Ismael M, Valenca RV, Machado JE, Maccariello E: Outcomes of critically ill patients with acute kidney injury and end-stage renal disease requiring renal replacement therapy: a case-control study. Nephrol Dial Transplant 2009, 24:1925-1930.

74. Lavaud S, Paris B, Maheut H, Randoux C, Renaux JL, Rieu P, Chanard J: Assessment of the heparin-binding AN69 ST hemodialysis membrane: II. Clinical studies without heparin administration. ASAIO J 2005, 51:348-351.

75. Cole L, Bellomo R, Hart G, Journois D, Davenport P, Tipping P, Ronco C: A phase II randomized, controlled trial of continuous hemofiltration in sepsis. Crit Care Med 2002, 30:100-106.

76. Payen D, Mateo J, Cavaillon JM, Fraisse F, Floriot C, Vicaut E: Impact of continuous venovenous hemofiltration on organ failure during the early phase of severe sepsis: a randomized controlled trial. Crit Care Med 2009, 37:803-810.

77. Ratanarat R, Brendolan A, Ricci Z, Salvatori G, Nalesso F, Cal M, Cazzavillan S, Petras D, Bonello M, Bordoni V, Cruz D, Techawathanawanna N, Ronco C Pulse high-volume hemofiltration in critically ill patients: a new approach for patients with septic shock. Semin Dial 2006, 19:69-74.

78. Honore PM, Jamez J, Wauthier M, Lee PA, Dugernier T, Pirenne B, Hanique G, Matson JR: Prospective evaluation of short-term, high volume isovolemic hemofiltration on the hemodynamic course and outcome in patients with intractable circulatory failure resulting from septic shock. Crit Care Med 2000, 28:3581-3587.

79. Cruz D, Perazella M, Bellomo R, de Cal M, Polanco N, Corradi V, Lentini P, Nalesso F, Ueno T, Ranieri VM, Ronco C: Effectiveness of polymyxin B-immobilized fiber column in sepsis: a systematic review. Crit Care 2007, 11:R47.

80. Cruz DN, Antonelli M, Fumagalli R, Foltran F, Brienza N, Donati A, Malcangi V, Petrini F, Volta G, Bobbio Pallavicini FM, Rottoli F, Giunta F, Ronco C: Early use of polymyxin $B$ hemoperfusion in abdominal septic shock: the EUPHAS randomized controlled trial. JAMA 2009, 301:2445-2452. 
81. Ronco C, Brendolan A, Lonnemann G, Bellomo R, Piccinni P, Digito A, Dan M, Irone M, La Greca G, Inguaggiato P, Maggiore U, De Nitti C, Wratten ML, Ricc Z, Tetta C: A pilot study of coupled plasma filtration with adsorption in septic shock. Crit Care Med 2002, 30:1250-1255. doi:10.1186/cc10499

Cite this article as: Hoste EAJ, Dhondt A: Clinical review: Use of renal

replacement therapies in special groups of ICU patients. Critical Care 2012,

16:201. 